\title{
Research on the Operation Mode and Countermeasure of Cross-Border E-Commerce Export Overseas Warehouse in China
}

\author{
Sihua $\mathrm{Xu}^{*}$, Juanjuan Liang \\ Economics and Management Department, Guangdong Polytech, Foshan City, Guangdong Province, \\ China \\ 10865057@qq.com,ljjgdfy@163.com
}

Keywords: Cross-border e-commerce, overseas warehouse, operating model, countermeasures

Abstract: With the rapid development of e-commerce, cross-border e-commerce is faced with a number of dilemmas, such as high cost, long delivery time and poor experience of buyers shopping experience. The new logistics mode of overseas warehouse solves the above problems to some extent, but the self-development of overseas warehouse is still full of difficulties. Through the analysis of advantages and disadvantages of overseas warehouses from multiple perspectives and actual survey data regarding cross- border e-commerce enterprises, this paper puts forward suggestions and thoughts on the healthy and sustainable development of cross-border e-commerce platforms and reasonable use of overseas warehouses to carry out business activities for sellers.

\section{Introduction}

There are a number of problems arising in the rapid development of cross-border e-commerce: poor time efficiency, high loss rate of goods, a lack of immediate feedback, high customer complaint rate and poor customer experience. There is urgency for merchants to fulfil those logistics distribution problems. While the emergence of the overseas warehouse logistics model has greatly enhanced the buyer's shopping experience and provided legal status for cross-border sales of Chinese goods and makes it possible for localized operations, overseas warehouses are still faced with enormous risks and challenges in their self-development.

\section{Definition and Operation Process of Overseas Warehouses}

Overseas warehouses are employed by local logistics companies to enhance customer experience by improving logistic efficiency, lowering logistics costs and offering refunds and after-sale services. In the meantime, logistics of high efficiency and decent customer experience is able to stimulate the upgrade of online businesses in return, thus leading to a drastic increase of cross-border e-commerce sales. 


\subsection{Definition of Overseas Warehouses}

Overseas warehouses are warehouses or storage places established or leased abroad. Cross-border e-commerce enterprises export goods in bulk to overseas warehouses for storage in the form of normal export trade. After receiving orders from overseas customers on the cross-border e-commerce platform, the sellers query the inventory of overseas warehouses through the logistics information system. The confirmed order then is transferred to the warehouse who is supposed to deliver the required goods to the corresponding domestic customers afterwards. After receiving the order, the warehouse will deliver the required goods to the corresponding customers and consumers through local logistics. In this process, the overseas warehouse is the overseas warehouse.

\subsection{Overseas Warehouse Operation Process and Function}

\subsubsection{Operation Process of Overseas Warehouse}

Overseas warehouses are an important part of cross-border e-commerce supply chain management, determining the speed and effectiveness of the entire cross-border supply chain.

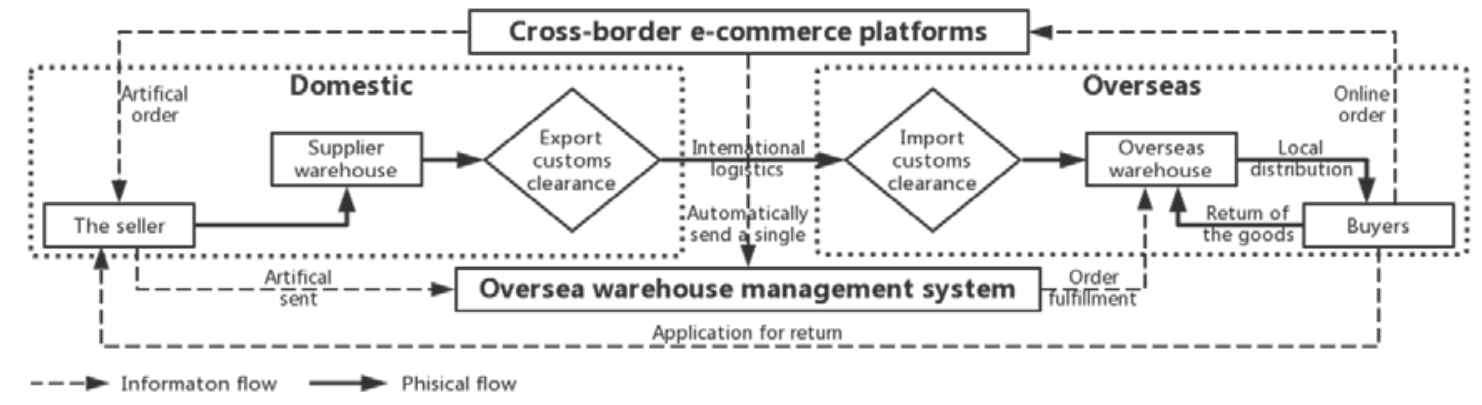

Figure 1 Flow chart of cross-border e-commerce export overseas warehouse operations

The basic process of cross-border supply chain (figure 1) is as follows: overseas buyers place orders on the cross-border e-commerce platform, sellers subsequently receive the orders, check the inventory and send orders to overseas warehouses. At the same time, both cross-border e-commerce platform and sellers can check order processing and inventory of warehouses through the integrated management system. After receiving the order, warehouses then deliver the goods through the local logistics enterprises or directly to the buyer if the inventory is satisfied. Meanwhile, sellers can place regular orders to the suppliers through an analysis of historical sales volume and sales forecast in the system. The third-party international logistics enterprise will take the goods from the supplier's warehouse and complete the delivery through the procedures of clearance, international logistics transportation, customs clearance, and finally to the overseas warehouse.

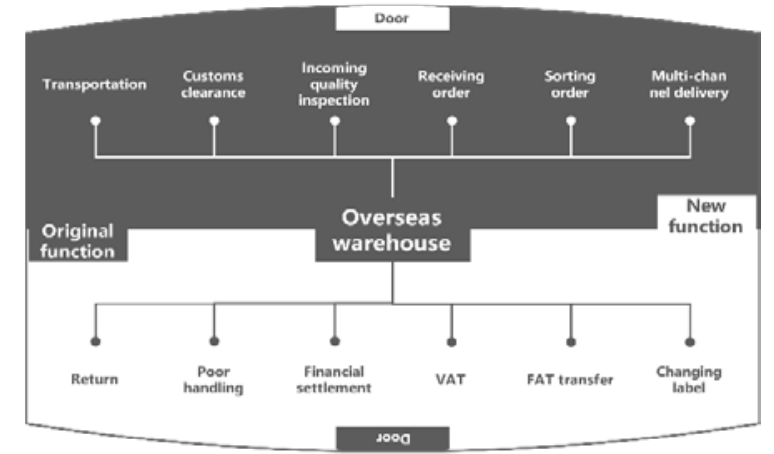

Figure 2 Function Diagram of cross-border e-commerce to export overseas warehouses. 


\subsubsection{Main Function of Overseas Warehouse}

Most overseas warehouses in addition to the storage of goods can also provide the seller with logistics services, like receiving orders, transportation, customs clearance, warehousing, quality inspection, order picking, multi-channel service delivery and others. With the continuous development of cross-border e-commerce, the function of the overseas warehouse also continuously extends, rising out of the return, the drug treatment, financial settlement, VAT, FAT transfer, trading standard and other value-added services. See Figure 2 for details.

\section{Classification of Overseas Warehouse Development and Operation Mode}

\subsection{Development of Overseas Warehouses}

Before 2002, some overseas students took their domestic products to foreign countries by means of "ant moving", and then sold them through online platforms, becoming the initial cross-border e-commerce merchants. Then, early sellers such as BFE, Zongteng and Aukey gradually took shape in their sales, and tried to sell the goods in the apartment and garage of overseas students, thus forming the earliest prototype of overseas warehouse. Subsequently, professional third-parties of overseas warehouses such as Chukou1 and 4PX EXPRESS appeared, starting the competition of overseas warehouses in cross-border e-commerce.

In recent years, cross-border e-commerce giants, such as Light in the box, Globalegrow, Youkeshu, Milanoo, Osell and Zongteng, have emerged. With their growing scale and huge sales, big sellers have started to build warehouses overseas, bring the first wave of self-built overseas warehouses. After 2014, Amazon FBA, eBay, Winit and other platform warehouses entered the market aggressively and seized a large number of markets. At the fourth session of the 12th National People's Congress in 2016, Premier Keqiang proposed in government work report that "business model innovation should be encouraged, pilot cross-border e-commerce should be expanded, and enterprises should be supported to build a batch of export products' overseas warehouses' to promote the development of comprehensive foreign trade service enterprises". The following year, Premier Keqiang mentioned cross-border e-commerce again in the government report, as one of the work projects of "adhering to the basic national policy of opening-up". In order to meet the development of e-commerce trend, combined with the government's vigorously advocated, the cross-border e-commerce platforms such as AliExpress, Cainiao network, JD global shopping and Vipshop have continuously expanded the market and set off a second wave of stock building boom.

\subsection{Operation Mode of Overseas Warehouses}

The development of overseas warehouses has been constantly upgraded with policy changes, with increasingly more functions and diversified business forms. Overseas warehouses can be divided in to three ways based on different business entities: renting, co-building and self-construction. They also have three categories based on the brands' forms of station: Amazon's FBA, the third-party cross-border warehousing enterprise and the self-built overseas warehouse. At present, the form of overseas warehouse in cross-border e-commerce is still constantly innovated, such as the integrated overseas warehouse allocation, the virtual overseas warehouse, the COD model of overseas warehouse, and the middle warehouse. This paper mainly analyzes the operation mode of overseas warehouse by the operation subject.

\subsubsection{Renting Overseas Warehouses}

Renting overseas warehouses is a common method in the early stage of China's export 
cross-border e-commerce development. It is the method that cross-border e-commerce companies rent a third party international logistics enterprise after comprehensive comparisons, managing storage by using the information system and management technology of the warehouse. In the meantime, cross-border companies are entitled to cover the costs of operation, logistics and storage. Newgistics and Spirit Warehouse Service Corporation are overseas Warehouse logistics Service providers in the United States. This kind of operation mode can offer the services of overseas collection, export declaration, international transportation, import customs clearance in the United States, e-commerce warehousing, order management, and e-commerce supply chain consulting services for long-distance delivery in the United States, meeting the needs of different customers (Meng Yuan, 2017).

With the continuous development and expansion, there is a deeper degree of logistics information sharing. Third party overseas warehouse gradually develops to provide domestic sellers with integrated supporting services with comprehensive cross-border solutions, thus forming a new mode of IWD warehouse, such as ChuKou1. Starting first with the expanding B2C business from cross-border warehouse, the company now has become one of the most trusted logistics service providers of cross-border e-commerce. Focusing on the global warehouse and integrating global resources of logistic supply chain, it is able to provide sellers with the services like overseas warehouse, FBA head range, the international line, international parcel, express delivery and localized pre- and after-sale service, solving many problems in order management and financing.

\subsubsection{Jointly Build Overseas Warehouses}

When renting overseas warehouses cannot meet their development needs and the conditions for building overseas warehouses are not mature, cross-border e-commerce enterprises can consider cooperating with third-party logistics service enterprises to build overseas warehouses. This form can improve the logistics, reduce the logistics time, greatly increase the supplier's gross profit, and at the same time, avoid the risk of trade barriers.

The construction of overseas warehouses generally requires the input of facilities, equipment, systems and even personnel by the third-party logistics service enterprises. Although cross-border e-commerce enterprises only need to cover the logistics and distribution costs, more efforts are required to improve the management of overseas warehouses and the logistics information system necessary(Rongjiao Yan,2016). The advantages of this mode is that it not only can fulfil cross-border companies' individuality demand to build a warehouse with unique design, but also can reduce construction and operation risks by the employment of third party logistics enterprises' professional skills, talents, experiences of logistics management, and exclusive geographical advantage.

For instance, EBay and Winit jointly set up overseas warehouses, and launched Winit American overseas warehouses platform for sellers, encouraging them to expand the north American market; Osell and XRU jointly set up overseas warehouses in Russia, providing systematic support and logistics convenience for its enter into the Russian wedding dress market(Wei Ye,2014). Through cooperation and joint venture, China Post Express builds overseas warehouses with multi-functional integration of storage, warehousing, packaging, tallying and distribution, and provides integrated solutions for third-party customers which are regarded as its first stop of its international network layout.

\subsubsection{Build Your Own Overseas Warehouse}

According to the overseas warehouse research report (Xianting Chen, 2017) (here in after referred to as the "report"), 55\% of sellers whose monthly sale is from $\$ 500000$ to $\$ 1$ million and $69 \%$ of sellers with the monthly sale more than $\$ 1$ million already have or have decided to build their own 
overseas warehouse; $38 \%$ of surveyed sellers stared to build their warehouses once the monthly sale reached $\$ 100000$.

(1) Seller's own construction

A seller's own construction refers to an overseas warehouse built in the overseas market by the big seller. After operating for a period of time, a large number of cross-border e-commerce sellers have successfully accumulated an amount of funds and built a strong client base. Therefore, the efficiency of logistics becomes the crucial factor for business with the rapid development of cross-border e-commerce. Sellers choose to invest in the building of overseas warehouses in areas where customers are concentrated, in order to realize the local delivery of goods and increase the delivery speed, thus improving customer satisfaction and building brand image.

(2) Transformation of cross-border e-commerce platforms

This type of platforms is built first from the transformation of early cross-border e-commerce companies from a simple platform to a large-scale enterprise with overseas warehouses. Because their better understanding of the situation and demands of cross-border e-commerce and relatively accurate grasp of the growing trend, this kind of platforms have the advantages in terms of marketing. Furthermore, as they are also cross-border e-commerce companies, their warehouses offer services for other e-commerce sellers instead of only for themselves.

\section{Advantages and Risks of Overseas Warehouse}

Before the emergence of overseas warehouses, the biggest problems faced by sellers using traditional express delivery methods are slow delivery speed, difficulty in tracking goods, slow clearance speed, easy damage and loss of goods, and difficulty in returns and exchanges of goods by buyers. The appearance of overseas warehouse perfectly solves the above problems and fully reflects the advantages of overseas warehouse.

\subsection{Advantages of Overseas Warehouses}

\subsubsection{Reduce Logistics Cost}

Big postal parcel and international railway logistics to transport goods have certain limitation of weight, volume and value, so the international express is the only way to deliver big ticket items and valuables. With the emergence of overseas warehouse, all those limits are removed, and the costs of logistics are reduced dramatically due to the batch transportation. Meanwhile, overseas warehouse ships goods from the resident country, which is equal to domestic distribution, thus lowering the costs.

\subsubsection{Improve Shopping to Experience}

The direct local delivery of overseas warehouses, without the complex operation processes of international long-distance transportation, customs declaration, customs clearance and trans-shipment, etc. ensures that the goods reach consumers faster, safer and more accurate, greatly reducing the delivery time; At the same time, because the overseas warehouse uses the local logistics service enterprise, it allows them to inquire the cargo delivery status online, increasing the transparency; There are various kinds of goods in the overseas warehouse, so it is easy to offer return and exchange services. The combination of overseas warehouse with Amazon FBA and traditional warehousing and logistics can avoid foreign trade risks and the logistics short board due to particular reasons like holidays. All these factors will bring good shopping experience to the buyer. 


\subsection{Risks of Overseas Warehouses}

The emergence and development of overseas warehouses perfectly solve the "bottleneck" problem of cross-border e-commerce logistics distribution, but at the same time, overseas warehouses gradually are faced with new risks and challenges in the development process.

\subsubsection{Serious Unsalable Inventory and Slow Market Response}

According to the data of the report (figure 3), on average, each cross-border e-commerce seller has 100,000 unsold inventory, some even up to several million. Faced with such inventory, $70 \%$ of sellers choose to sell at a low price, $19 \%$ choose to destroy, and $11 \%$ choose other ways of handling. The survey also showed that most sellers could not predict the cargo demand of overseas customers based on the data returned from overseas warehouses, nor could they grasp the shopping preference of overseas consumers. However, the quantity of goods in stock and the delivery cycle of cross-border e-commerce sellers are exactly predicted based on the demand and preference of overseas consumers. If the prediction is not accurate, cross-border e-commerce sellers will have to bear a series of unnecessary operating costs, such as inventory, product recycling or overseas destruction.

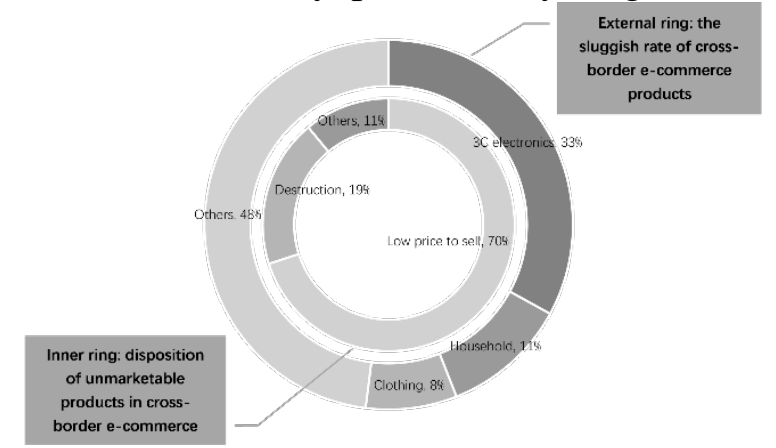

Figure 3 Unsalability rate and disposal of cross-border e-commerce products

The main reason for this phenomenon is that cross-border supply chain has many links, a long span and obvious bullwhip effect. Relying on overseas warehouse logistics data cannot make stock prediction, and at the same time as a result of long lead time of overseas warehouse and seasonable characteristics of a certain number of goods, e- errors often occurs while cross-border e-commerce sellers making decisions. As time passes, the accumulation of errors eventually leads to a large backlog inventory of goods.

\subsubsection{Low Level of Service and Lack of Competitiveness}

According to the data of overseas warehouse delivery in the report, 55\% of sellers will regard FBA as the main overseas warehouse delivery method. For these sellers, the proportion of the shipment of self-built warehouses is about $10 \%$ to $30 \%$. Meanwhile, $67 \%$ of sellers using FBA and self-built warehouses will not choose third-party warehouses. 


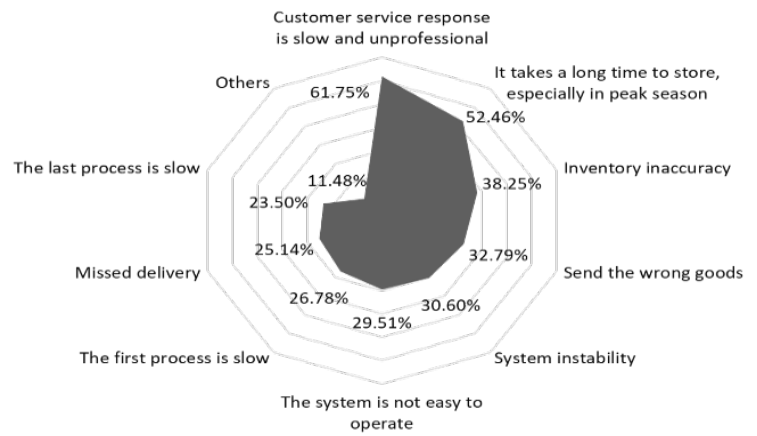

Figure 4 Distribution of complaints from cross-border e-commerce sellers to third-party service providers

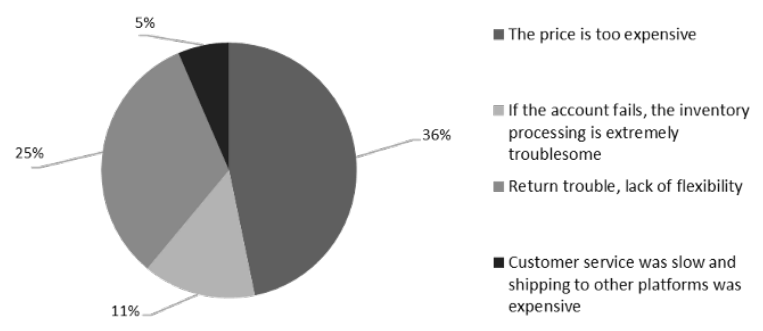

Figure 5 Distribution diagram of complaints about FBA by cross-border e-commerce sellers

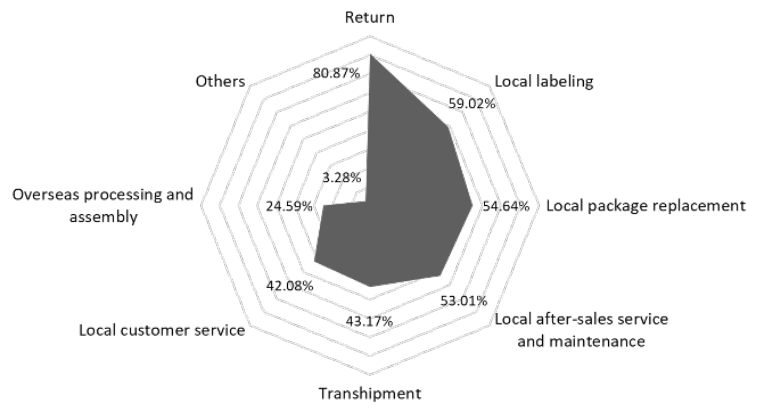

Figure 6 Distribution of personalized service demands of cross-border e-commerce sellers

It can be seen from figure 4 to figure 6 that (1) the sellers are very dissatisfied with third-party overseas warehouses and amazon FBA for many reasons. (2) Strong demand for personalized service from sellers. (3) Although FBA's warehouse resources are not satisfactory, it still has a great advantage over third-party overseas warehouses.

In addition, the sellers who have self-built overseas warehouses are mostly FBA, with self-built as the auxiliary; Most sellers do not choose third-party overseas warehouses. It can be seen that the service level of the third-party overseas warehouses is low and they lack competitiveness, which ultimately affects the choice of logistics distribution mode of cross-border e-commerce sellers.

According to the investigation and analysis, the third-party overseas warehouses in the overseas market are in the period of heavy investment and construction with little output. In the future, in order to the competition, it is significant to improve the service level, cultivate the core competitiveness and meet the personalized demands of sellers.

\subsubsection{Lack of Localization and Taxation and High Risk of Supervision}

Thirty percent of sellers in the report were concerned about policy supervision and tax risks, while 30 per cent were concerned about the risk of unsold goods. In addition, there are risks such as capital pressure, cargo safety and poor management. Since 2017, European tax policy on cross-border e-commerce has become stricter. Overseas warehouses in major cross-border e-commerce markets 
such as the UK, Germany and France have been hit by tax waves of different degrees. The Russian government has started to check the "grey customs clearance" from April 2018, and the overseas warehouses would be closed permanently if they are involved. Due to the non-compliance of cross-border e-commerce sellers in overseas taxation, overseas customs clearance and warehousing and logistics enterprises have to bear the tax risk of the entire supply chain (Kang Sun, 2016).

Compared with other logistics modes of cross-border e-commerce, such as direct delivery of small packages and private lines, cross-border e-commerce enterprises that are based on the overseas warehouse delivery mode are basically enterprises registered with their real names outside China. Therefore, tax compliance and localized operation are more urgent. The successful sellers finally achieve the ultimate goal by implementing the localization strategy and using the overseas warehouse to realize the convenience of foreign consumers to buy overseas products just like local shopping.

\section{Development Ideas of Overseas Warehouses}

\subsection{Competition and Cooperation Shall Complement Each Other and Give Play to the Synergistic Advantages of Supply Chain}

Many small and medium-sized cross-border e-commerce enterprises, without the ability to build overseas warehouses, consider the combination of border warehouses and overseas warehouses, that is, to set up a warehousing base within the territory of China close to the neighbouring countries, from which the goods are delivered through postal parcels to the whole territory of the neighbouring countries (Ranzhe Jing, 2016). At the same time, there is another choice of leasing border warehouses, cooperating with overseas warehouses, and complementing Amazon FBA. One of the main sources of revenue for overseas warehouse is the services of FBA's initial stage, return and replacement, and bid exchange; FBA defaults to separate warehouses and third-party overseas warehouses will generally put the goods in the same warehouse for centralized management; In addition, FBA has introduced a new charging concept -- Inventory Storage Overage fee. If goods are kept in amazon warehouse for a long time, additional costs will be incurred. According to these different policies, third-party overseas warehouses and FBA can form the relationship of complementarities rather than just competition.

Cross-border e-commerce supply chain mainly includes merchants, cross-border e-commerce platforms, logistics service providers (domestic and foreign postal enterprises and transit enterprises), and overseas warehouses, etc. Supply chain coordination is to connect all node enterprises to achieve information sharing between nodes, so as to achieve maximum utilization of resources. In the process of the implementation of supply chain collaboration, overseas warehouses need to improve the service efficiency, optimize the customer service level, pay attention to front-end and back-end customer experience, ensure the cooperating allocation and complementation of weaknesses, integrate storage and transportation, achieve the goal of intelligent replacement of goods in overseas warehouse through comprehensive information services platforms ( or ERP system), thus promoting overseas warehouse operations and effectively coordinating types of supply chain.

\subsection{Use Information Technology to Establish a Big Data Platform}

In order to give play to the advantages of overseas warehouses, sellers need to use the support of advanced information technologies such as cloud computing, Internet of things and big data to build a big data platform consisting of a smooth logistics and warehousing network system, a high-quality and efficient logistics operation service system and an interconnected intelligent logistics information system.

The overseas warehouse makes use of the big data platform to visualize the various attributes of 
the data through charts, assisting the cross-border e-commerce sellers to have a plain understanding of the demands of overseas consumers and make accurate demand prediction, so as to solve the problems of prolonged capital turnover cycle and increased cost brought to cross-border e-commerce sellers by unsalable goods. The seller makes use of the platform data and adopts a reasonable and perfect stocking strategy, so as to realize the selection of goods and accurately predict the replenishment cycle. An analysis of the time points in the process through data management logistics can be adopted as well to identify problems in the delivery process, finished product delivery process and other aspects. Sellers can also optimize the process and improve efficiency in supply chain management, inventory level control and moving sales management.

\subsection{The Construction of Warehouses should be Cautious and the Construction of Warehouses Should be closer to National Policies}

The report shows that in developed western countries, the cost of manpower and the rent of warehouses is high, and the construction of overseas warehouses is affected by local culture, language, customs, policies, laws, taxes and other factors. Therefore, the construction of self-built overseas warehouses should be cautious, and the comprehensive inspection, overall analysis and all-round comparison should not be conducted blindly. Figure 7 shows that the United States is basically saturated with overseas warehouses, while other developed countries are constantly improving their overseas warehouses.

In the process of selecting locations to build warehouses, big sellers and super cross-border e-commerce platforms, on the one hand, should take national policy orientation into account; on the other hand, they should look for overseas warehouses to build a new territory for cross-border e-commerce. China, under the circumstances of advocating "the Belt and Road Initiative" construction, is strengthening the relationship and cooperation with the countries and districts along the " belt" by building cross-border e-commerce localization service networks in countries like India, Russia, Poland, Dubai, Canada and Brazil. In this kind of constructions, there is a need for a group of innovative with strong business strength familiar with cross-border business. The government has issued policies to support the development of overseas warehouses by offering special funds, encouraging organized enterprises to integrate "Internet plus" into the construction of overseas warehouses, cultivating a number of third-party overseas warehouses with high efficiency, standards and strong service awareness, creating friendly environment for small, medium and micro enterprises to go out, and improving the global reasonable layout of overseas warehouses. In the end, a new mode of overseas warehouse sales in line with local customs and practices and consumption habits will be formed to achieve the comprehensive development of cross-border e-commerce and make Chinese products go global.

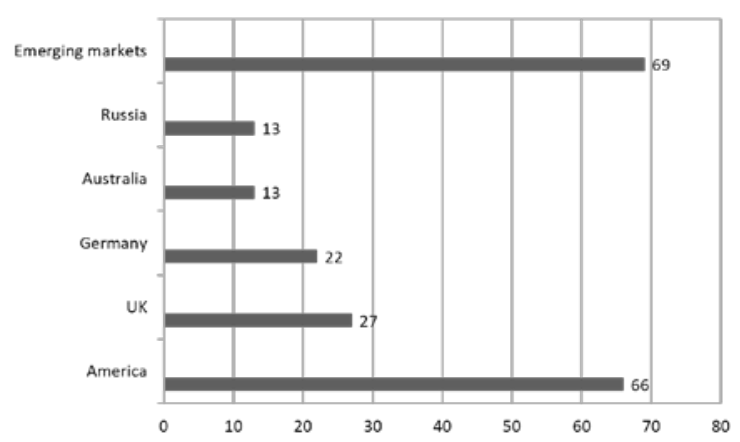

Figure 7 Distribution of 210 third-party warehouses around the world. 


\section{Acknowledgements}

This paper is supported by the project fund of "B2C cross-border e-commerce industrial chain optimization and competitiveness" (YQ2015180) funded by the Training Program of Outstanding Young Teachers in Guangdong Provincial Institutions of Higher Learning.

\section{References}

[1] Kang Sun, 2016. Research on the countermeasure of the future development and pros and cons analysis of oversea warehouse, Foreign Economic Relations \& Trade. (6), pp. 29-31.

[2] Meng Yuan, 2017. Research on the construction and development stragtegy of cross-border e-commerce oversea Warehouse, Sci-Tech Innovation \& Productivity. 01(276), pp. 30-33.

[3] Ranzhe Jing, 2016. Cross-border e-commerce operation and case, China gongxin publishing group/Electronic industry press. Beijing, 1st edition.

[4] Rongjiao Yan, 2016. Study on the construction modes of overseas storage of cross-border logistics in China. Anhui University.

[5] Wei Ye, 2014. Research on the development strategy of postal express logistics enterprises under cross-border e-commerce environment. Shandong Normal University.

[6] Xianting Chen, 2017. Shenzhen YiCang Tech Co., Ltd, The overseas warehouse research report. Available from: http://www.eccang.com. 